\title{
Water Oxidation through Interfacial Electron Transfer by Visible Light Using Cobalt-Modified Rutile Titania Thin-Film Photoanode
}

Hideyuki Tanaka, ${ }^{1}$ Tomoki Uchiyama, ${ }^{2}$ Nozomi Kawakami, ${ }^{2}$ Megumi Okazaki, ${ }^{1,3}$ Yoshiharu Uchimoto, ${ }^{2}$ Kazuhiko Maeda*1

${ }^{1}$ Department of Chemistry, School of Science, Tokyo Institute of Technology, 2-12-1-NE-2 Ookayama, Meguro-ku, Tokyo 152-8550, Japan

${ }^{2}$ Graduate School of Human and Environmental Studies, Kyoto University, Nihonmatsu-cho, Yoshida, Sakyo-ku, Kyoto 606-8317, Japan

3 Japan Society for the Promotion of Science, Kojimachi Business Center Building, 5-3-1 Kojimachi, Chiyoda-ku, Tokyo 102-0083, Japan

*To whom corresponding author should be addressed. maedak@chem.titech.ac.jp 


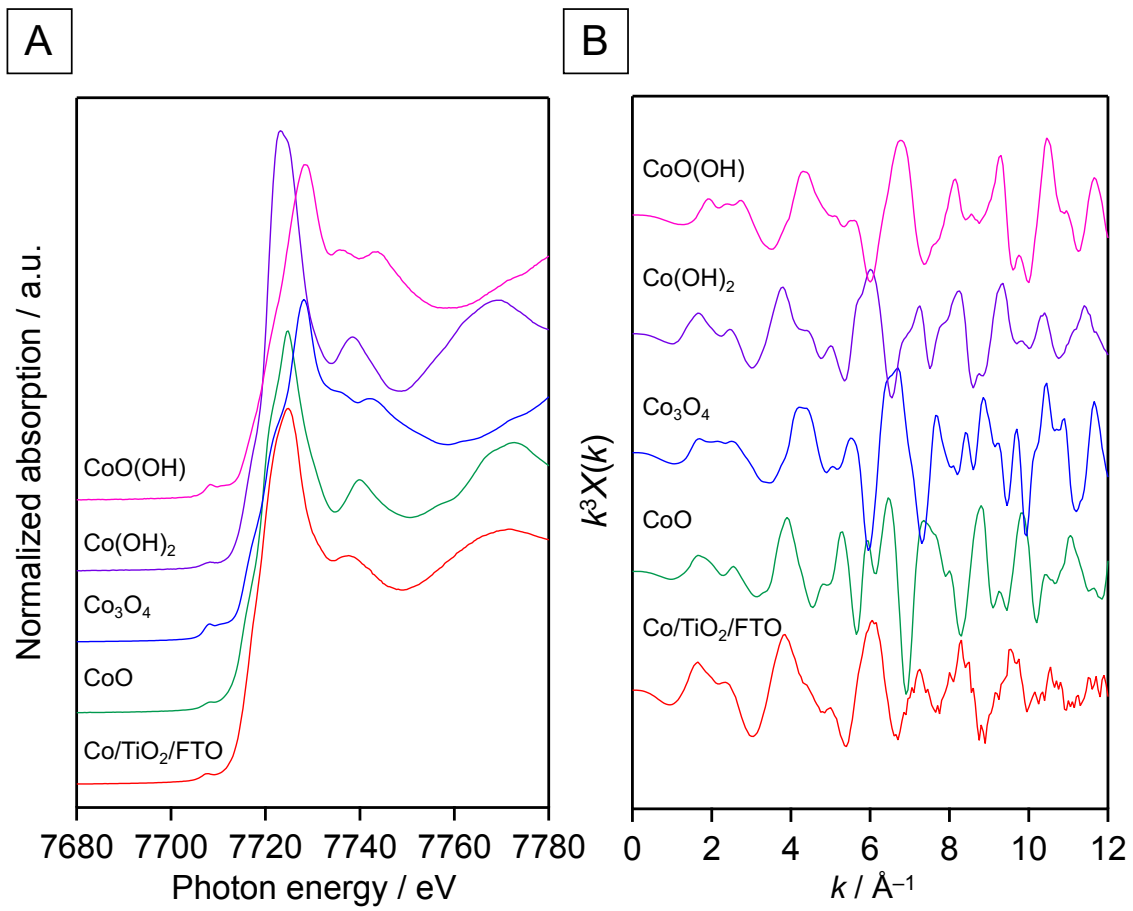

Figure S1. Data acquired from XAFS analyses. (A) Co K-edge XANES spectra and (B) EXAFS spectra. The $\mathrm{Co} / \mathrm{TiO}_{2} / \mathrm{FTO}$ electrode was prepared at $0.15 \mathrm{M} \mathrm{TiCl}_{4}$ concentration.

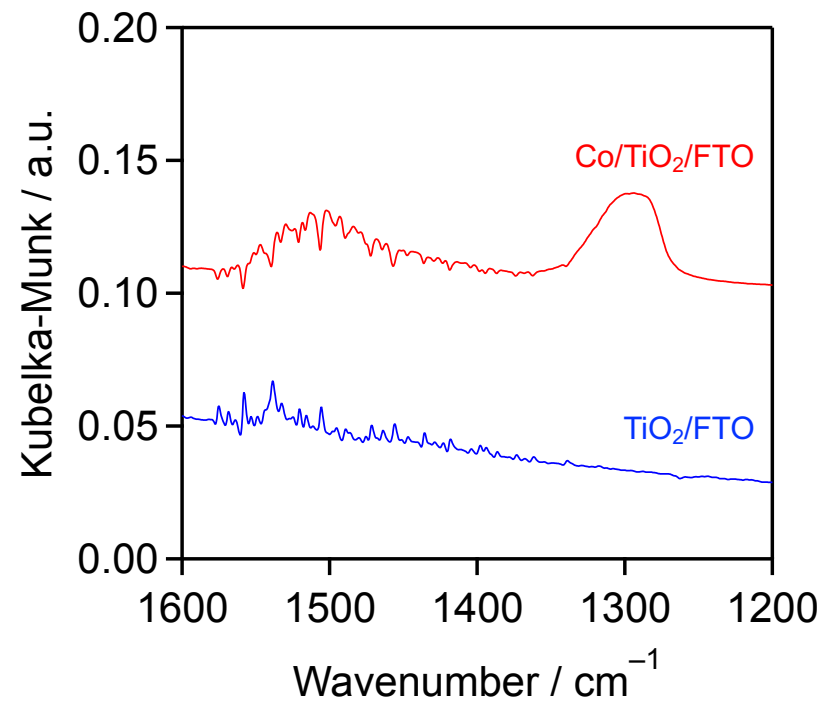

Figure S2. FT-IR spectra for the $\mathrm{Co} / \mathrm{TiO}_{2} / \mathrm{FTO}$ and $\mathrm{TiO}_{2} / \mathrm{FTO}$ electrodes. The spectra were acquired in a diffuse reflectance mode. Two peaks appearing at around 1300 and $1500 \mathrm{~cm}^{-1}$ in the $\mathrm{Co} / \mathrm{TiO}_{2} / \mathrm{FTO}$ electrode are assignable to nitrate species bound to cobalt in $\alpha-\mathrm{Co}_{3}(\mathrm{OH})_{4}\left(\mathrm{NO}_{3}\right)_{2}$ (see J. Solid State Chem. 2006, 179, 2386-2393). 

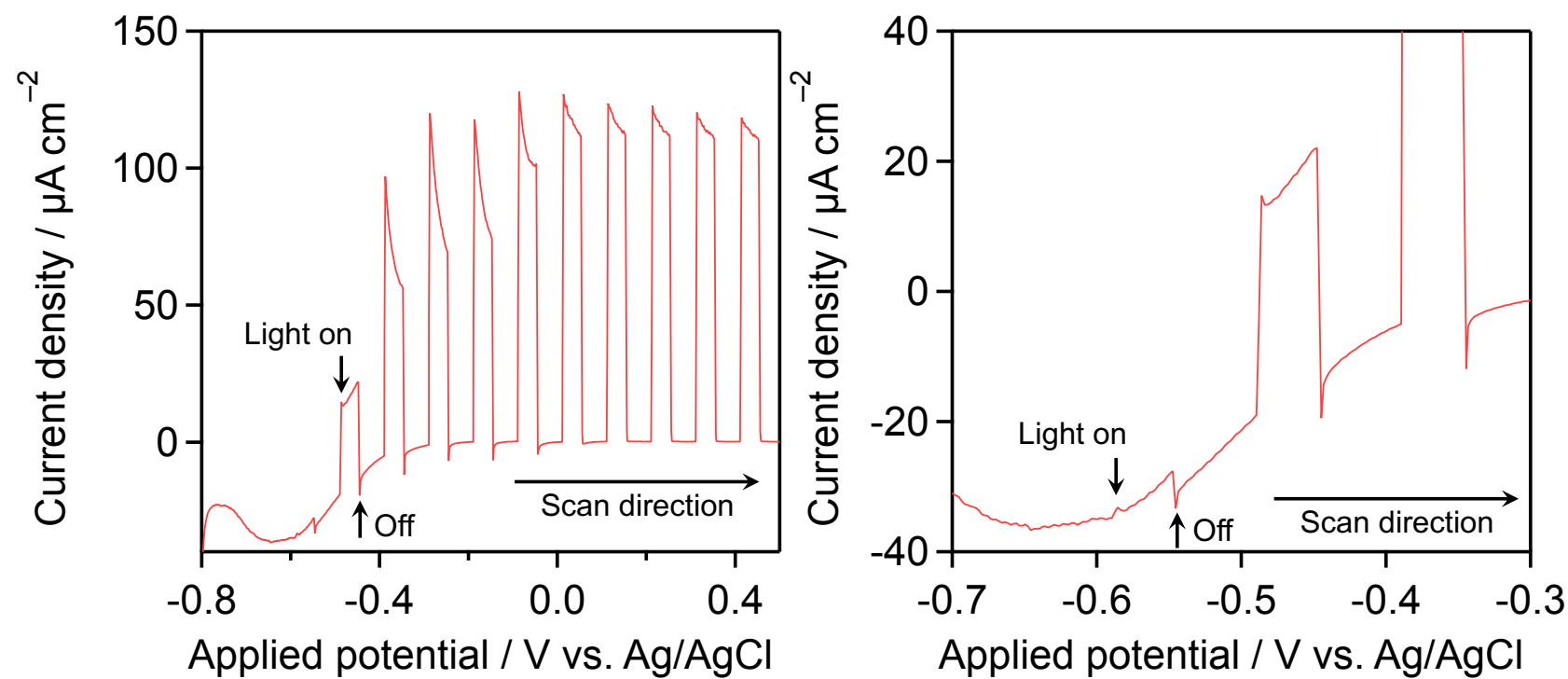

Figure S3. Current-voltage curve for the $\mathrm{TiO}_{2} / \mathrm{FTO}$ electrode measured in $0.1 \mathrm{M}$ aqueous sodium phosphate solution ( $\mathrm{pH}$ 9) under intermittent UV irradiation. Scan rate: $20 \mathrm{mV} \mathrm{s}^{-1}$. Light source: $300 \mathrm{~W}$ xenon lamp. The photocurrent onset potential was ca. $-0.6 \mathrm{~V}$ vs. $\mathrm{Ag} / \mathrm{AgCl}$, which corresponds to ca. $+0.1 \mathrm{~V}$ vs. RHE.

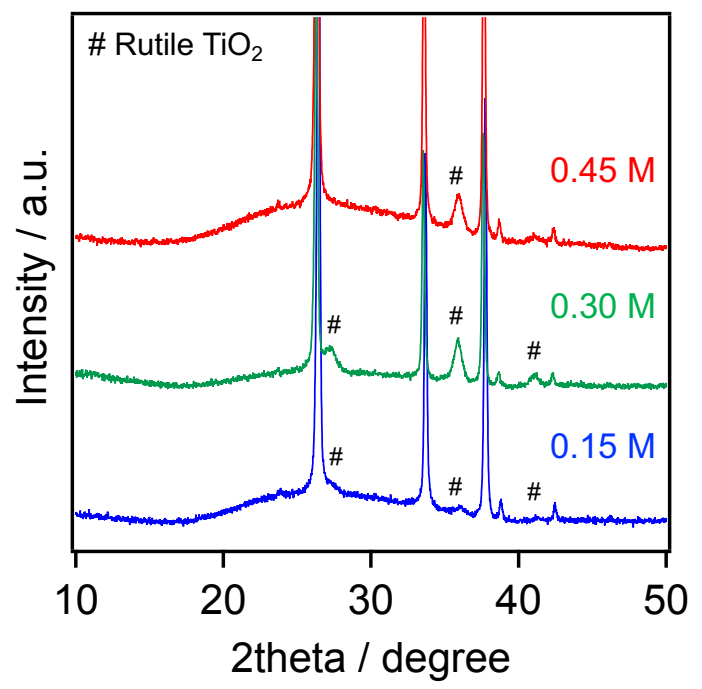

Figure S4. XRD patterns of $\mathrm{TiO}_{2} / \mathrm{FTO}$ electrodes prepared at different $\mathrm{TiCl}_{4}$ concentrations. 


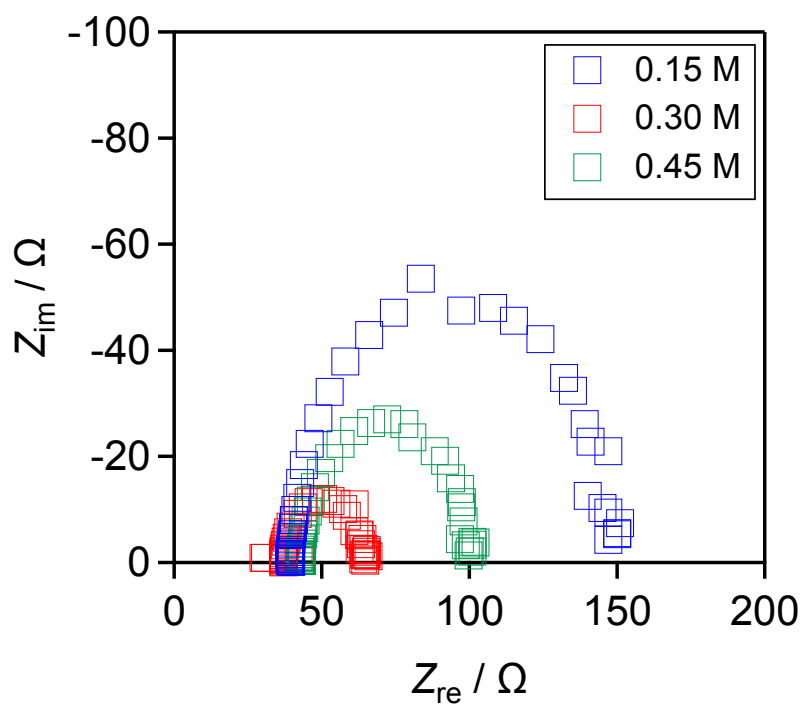

Figure S5. Nyquist plots for $\mathrm{TiO}_{2} / \mathrm{FTO}$ electrodes prepared at different $\mathrm{TiCl}_{4}$ concentrations. The plots were acquired at room temperature in aqueous $0.1 \mathrm{M} \mathrm{Na}_{2} \mathrm{SO}_{4}$ solution containing $3 \mathrm{wt}_{0} \% \mathrm{H}_{2} \mathrm{O}_{2}$ at +0.5 $\mathrm{V}$ vs. RHE under UV irradiation $(\lambda>350 \mathrm{~nm})$. Note that it was difficult to perform a reasonable fitting analysis for each plot. Nevertheless, the overall shape of the Nyquist plot arcs should reflect the total resistance of the charge transfer processes.

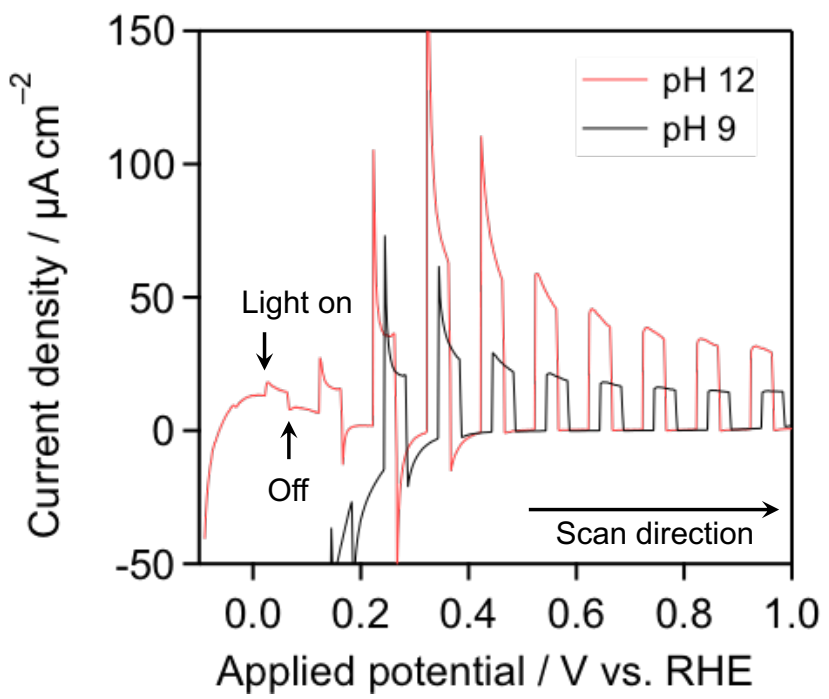

Figure S6. Current-voltage curves in aqueous electrolyte solution at different $\mathrm{pH}$ values under intermittent visible-light irradiation for $\mathrm{Co} / \mathrm{TiO}_{2} / \mathrm{FTO}$ electrodes prepared at $0.30 \mathrm{M} \mathrm{TiCl}$ concentration. Scan rate: $20 \mathrm{mV} \mathrm{s}^{-1} \cdot \mathrm{pH} 12, \mathrm{Na}_{2} \mathrm{HPO}_{4}-\mathrm{NaOH}$ mixed solution $\left(\left[\mathrm{PO}_{4}{ }^{3-}\right]=0.1 \mathrm{M}\right) \cdot \mathrm{pH} 9, \mathrm{Na}_{2} \mathrm{SO}_{4}-\mathrm{NaOH}^{-}$ mixed solution $\left(\left[\mathrm{SO}_{4}{ }^{2-}\right]=0.1 \mathrm{M}\right)$. 


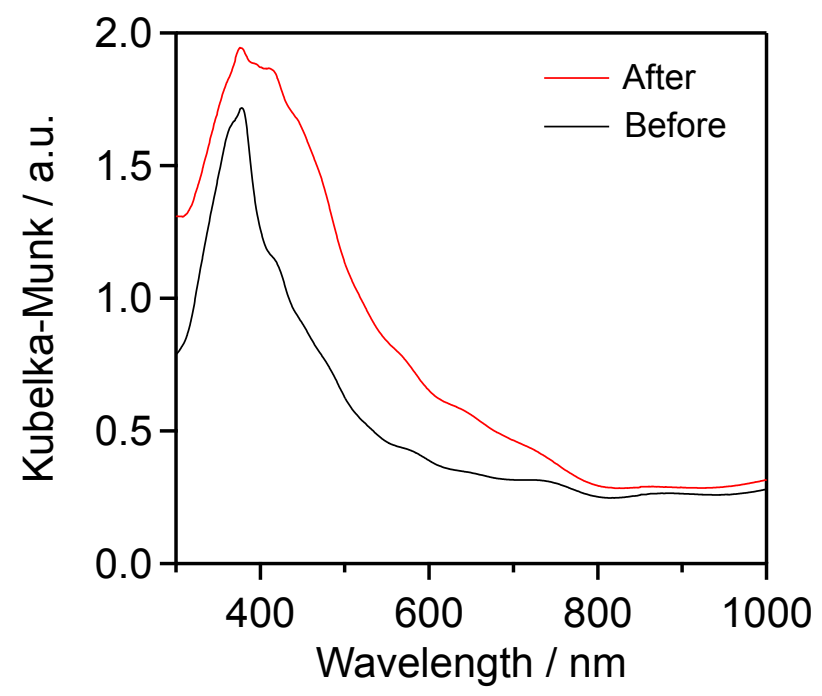

Figure S7. UV-visible diffuse reflectance spectra of the $\mathrm{Co} / \mathrm{TiO}_{2} / \mathrm{FTO}$ electrodes prepared at $0.30 \mathrm{M}$ $\mathrm{TiCl}_{4}$ concentration before and after photoelectrolysis at $\mathrm{pH} 12$ in a $\mathrm{Na}_{2} \mathrm{HPO}_{4}-\mathrm{NaOH}$ mixed solution $\left(\left[\mathrm{PO}_{4}{ }^{3-}\right]=0.1 \mathrm{M}\right)$. 